\title{
THE CONTRIBUTION OF TECHNOLOGY TO AN UNDERGRADUATE INTERNATIONAL LEARNING PARTNERSHIP: THE RITUAL PERSPECTIVE
}

\author{
Liene Ločmele \\ Vidzeme University of Applied Sciences, Latvia \\ University of Massachusetts-Amherst, United States \\ Barbara Ruth Burke \\ University of Minnesota, Morris, United States
}

\begin{abstract}
This study is part of a research project on a learning partnership between undergraduates of ViA, Latvia and UMM, USA. During the joint media course in Spring 2016, students participated in Skype discussions, completed shared assignments and reflected upon their learning experience. The transcripts of these activities form the body of qualitative data. We employ the perspective of Ethnography of Communication (Hymes, 1962; Philipsen, 1997) and Cultural Discourse Analysis (Carbaugh, 2007) in order to answer the following research questions: (1) what is the nature of the studied technology-mediated learning discourse, and (2) how do the constructed meanings around the use of technology contribute to the variety of cultural norms in play? We propose to understand the studied discussion sessions as a ritual practice (Turner, 1980; Philipsen, 1992, 1997)-the correct performance of which the participants instantly co-construct and negotiate when employing locally-adopted norms associated with democratic education practice-and assess the use and function of technology in the experienced learning interactions.
\end{abstract}

Keywords: Cultural Discourse Analysis, Ethnography of Communication, Ritual, Undergraduate Teaching.

\section{Introduction}

In the center of this study is the technology-mediated learning interaction activities which happened during the planned, real-time pairing of two Media Studies undergraduate courses that took place at Vidzeme University of Applied Sciences (ViA), Latvia and University of Minnesota-Morris (UMM), USA in Spring 2016. Both schools are small but locally well-recognized regional institutions of higher education that offer a similar scope of study programs and host local as well as international students. The majority of students at both institutions are undergraduates, mostly aged 18-25. In our analysis we employ Ethnography of Communication (Hymes, 1962; Philipsen, 1997) and Cultural Discourse Analysis (Carbaugh, 2007) in order to systematically explore the 
symbolic meanings constituting the communication practices that these participants used to take part in and to make sense of their joint learning process. The study is generally guided by following research questions: (1) what is the nature of the studied technology-mediated learning discourse, and (2) how do the constructed meanings around the use of technology contribute to the variety of cultural norms in play?

The qualitative data of this analysis include audiovisual recordings of Skype discussions between both groups of students (on average 60 participants in total); the written content of learning journals; audio-recorded student reflectiondiscussions, along with written group reflections on the process and content of the course's international components; and instructors' ethnographic observations of the overall experience.

The study is inspired by a recent debate in the communication discipline about whether globalization of education facilitates the equal exchange of ideas and culture or, on the contrary, perpetuates already determined power relations that stems from US-based intellectual politics and interests (Waisbord, 2016). While keeping in mind the potential implications of the aforementioned power dynamics for the studied communication practice, here we are first and foremost concerned with an in-depth description and interpretation of our data that forms the first stage of this ongoing project.

\section{Theoretical Frame and Method}

This study is primarily theoretically grounded in the discipline of Communication. We borrow from the field of Education research when considering that people will perform culturally and socially-constructed roles based upon their understandings of and interpretations of a relational situation, and that a classroom has situations and settings familiar to particular students and instructors. As Cazden (2001) suggests, the customary assortment of classroom discourse patterns are familiar and predictable for educated participants, involving the shared understandings of negotiated positions, relationships and values that make up the learning environment. It is also understood that participants perform within the context that pre-defines opportunities and possibilities created institutionally (e.g., Cameron, 2000) where teacher-lecturing courses, using "ordinary classroom talk" sometimes have the tendency to replicate hegemonic processes and reinforce power relationships (e.g., Alexander, 1999; Brasswell, 2015; Maybin, 2013, Damrow, 2014).

The perspective of Ethnography of Communication (Hymes, 1962) has been previously used to understand the communication in country-specific and culturespecific higher education contexts. For example, by comparing Blackfeet (Native American) communication in a Public Speaking classroom to Anglo-American 
student performance, Carbaugh identifies a communication code of "expressive separateness" that, among other spheres, constitutes the heart of American democratic institutions, universities included. It presumes that persons are separate and extricable entities; social persons, positions and relations need to be built or worked upon; feelings stem from within; and communication is the means of connecting persons, forging relations, expressing feelings, and bettering one's social standing (Carbaugh, 1993).

Extending the Ethnography of Communication to critically examine preexisting power struggles, Covarrubias (2008) described masked silence as a discriminatory practice in everyday college classroom activities. Furthermore, (e.g. Finnish-American communication studied by Carbaugh 2005, Carbaugh et.al 2006), it has been applied to understand the cultural differences in communication experienced by exchange students upon interacting with counterparts at their host countries. The commonality among these is the orientation towards a single physical context - a university environment with a variety of groups presented in the learning situation. Those situations are ideologically-specific to a particular national context where the studied communication takes place. Our study focuses on communication that has no singular physical place of existence, since the communication between groups of students from ViA and UMM is a product of technology-mediated real-time interaction-this construction foregrounds a set of cultural norms along with having the potential to creatively negotiate them.

The embedded assumptions of institutional powers are also important contextual factors shaping communication rituals, since we both teach at public/ state-supported schools. Increasingly in higher education, it has been asserted that "in the U.S., citizens should be educated in ways that are consistent with the political ideals of the nation, including reasoned and rational civic engagement and a commitment to democratic ideals such as justice and equality for the promotion of an American identity" (Schildkraut, 2007; Spencer, 2011 cited by Obenchain et.al., 2016: 252). Historically Latvian higher education institutions had to adjust to new political situations repeatedly over a short period of time, adopting education models from other countries (Dedze \& Rubene, 2016). The Post-Soviet period can be most characterized by the promotion of international cooperation with the democratic world and the purposeful internationalization of university activities. After joining the European Union in 2004, these processes led to the development of a local model of higher education in Latvia, namely, to the transformation of borrowed ideas to fit the context of local system of education (ibid.). Despite these factors, both ViA and UMM broadly can be characterized as having common general principles of democratic education, the learning interaction in the scope of our study focuses mostly upon the specific enactments and interpretations of the said principles that the studied partnership and created communication situation illuminates. 
In this project, the notion of culture builds on ideas from Cultural Discourse Analysis (CuDA) and Speech Code Theory, both rooted in the discipline of Ethnography of Communication. They approach culture as a part and product of discursive systems. CuDA follows the definition of culture as a "potentially integrative and changeable system of symbols, symbolic meanings and forms that are mutually intelligible, commonly accessible, deeply felt and historically grounded" (Carbaugh, 1993, 2007). Philipsen defines culture as a code, "a particular system rather than a geographical or political unit in which it is found" (Philipsen, 1997: 125). We thus see discourse as "culture in conversations" (Carbaugh, 2005). The communication in which our participants engaged during their joint tasks is the conversation where one or more cultures are always in play in other words, the conversation always belongs to wider cultural systems (ibid.).

Specifically, we build our analysis around Philipsen's suggestion to focus on meta-communicative vocabulary or "talking about talk" as being a productive departure point for understanding peoples' social realities. Philipsen defines speech codes as "system of socially constructed symbols and meanings, premises and rules, pertaining to communicative conduct" (Philipsen 1997: 126). For Philipsen, the significance of speaking depends on the used speech codes that allow interlocutors to constitute the meaning of a particular communicative act (ibid.).

Philipsen $(1992,1997)$ refers to ritual as one of the culturally distinctive forms of communication where one can hear a particular speech code being articulated. He notes that this rather routinized episodic sequences demand particular knowledge about cultural ways of speaking and interacting. Philipsen also uses Turner's definition of ritual as "structured sequence of actions the correct performance of which pays explicit homage to a sacred group or culture" (as cited in Philipsen, 1997: 144). Hall (2005) notes that it is false to assume that rituals are essentially outdated, meaningless, hypocritical, reserved for special settings or performed by those less sophisticated than us. He points at the universal nature of the ritual since as a form of communication it is an inevitable part of humans' mundane, everyday interaction. Ritual is repetitive as a type of communication but not by its content, thus, there is always room for creative expressions of all parties involved in the performance of the ritual in question (ibid.)

We use our participants' repetitive descriptions of themselves and international partners as being "shy" at a number of situations during the joint technology-mediated discussion sessions as our departure point. Among the defined sites of speech codes, Philipsen (1997) suggests to look for the rhetorical invocation of meta-communicative vocabularies where the speech code elements are expressed in the naming, interpreting, explaining, evaluating and justifying of communicative acts (ibid.). We see our participants' using of term "shy" as being 
aforementioned invocation that allows us to access the cultural premises of existence (what is), and of value (what is good and bad) (ibid.) that pertain to the symbolic negotiation of the "correct performance" of the discussion session ritual.

In our analysis firstly, we explore the notion of "shy" as a metacommunicative term allowing us to describe and interpret the cultural premises that the use of the term brings to the surface of the studied discourse. Then, we approach the classroom interaction as a ritualized practice enabled by the discovered cultural premises that guide the participants' performance and evaluation of it. Finally, we elaborate on the meanings associated with the use of technology, as they are understood by our participants. Like Foucault and Melican (2007) we see communication technologies as participating in the construction and maintenance the social life of the classroom by supporting and extending the already existing ritualized practices.

\section{Results}

Students and instructors who operate in a democratic higher education environment often use descriptions of the verbal engagement of themselves and others in discussion sessions in order to explain and assess their learning experiences. While there are variations across locations, institutions, study disciplines and subject cultures, group dynamics and individual practices, it is rather safe to say that generally both students and instructors routinely engage in discussion sessions and recognize a good one when they experience one. It is a popular practice to provide young teaching professionals and other interested parties training in how to lead a discussion session. It is also a common practice for universities to organize introductory seminars on local academic requirements for their exchange students, often including familiarization with the norms and rules associated with in-class participation. Bearing these notions in mind, we do not attempt to discover a novel ritualized practice of a university discussion session. Instead, we enter the analysis with the idea of a discussion session as an already-existing routinized and ritualized practice that celebrates the values associated with democratic education - sharing, equal participation, coconstruction of knowledge, and egalitarian relationships. When both of our student groups communicated, they brought to their interaction culturally rich ways of communicating and interpreting the said ritualized practice. The cultural premises that our analysis will eventually define can be used as guidelines to understand the cultural specifics of the content of this structurally rather unified practice. 


\section{Description}

In the following excerpts ViA (LV) and UMM (US) students invoke concerns when referring to their interaction in Skype discussion sessions as somehow not fitting into the unspoken yet expected pattern of classroom behavior, since participants came across to each other as being "shy", unable to "speak much" or were "listening" when some other form of participation was apparently recognized as more suitable:

"[...] of course, the language issues stopped Latvian students from speaking much and American students were speaking more, but in other hand, discussions in English helped improve our language knowledge" (LV13 - Learning Journal).

"They [ViA students] were a little shy at first, their English tongues varying around the classroom, and were also kind and respectful, listening to our questions and answers intently (US6 - Learning Journal).

"[...] what was new for me - they [UMM students] were a little bit shy, no one of them did not want to sit in the front and sometime there were silent moments in their class after lector asked a question for them" (LV5 - Learning Journal).

In the first excerpt ViA student (LV13) describes his own group as not being able to "speak much" due to the "language issues". While recognizing this situation as being problematic, the student is prizing a possibility to "improve" by being able to be present in classroom discussions. This suggests that a mere physical presence and listening to what has been said is somehow an insufficient form of participation yet points at it also as the possibility for growth.

Similarly, UMM student (US6) in the second excerpt problematizes the ViA side as initially being "a little shy" since different students had various degrees of English skills. However, the failure to deliver the proper amount of talk seems to exceed the scope of English proficiency since in the final evaluations of the courses' international partnership component both sides expressed positive surprise about their capabilities to communicate in English and the language issue was never brought up as something that for participants would be a significant restriction for their ability to interact and learn.

The third excerpt speaks to "shyness" manifesting itself in the form of "silent moments" that followed the instructor's questions as perceived by ViA student (LV5) on UMM side. This signal tells about shared classroom rules being at play and violated by a student failing to deliver the response in an expected timely fashion.

Additionally, the ViA student (LV5) in the third excerpt has noticed that UMM students were also "shy" since they avoided "to sit in the front" of the classroom. It has to be noted that Latvian students were also hesitant about picking 
seats in the front lines, recognized their behavior as being problematic by joking about it off-record, and generally complaining about the class being held in large auditorium with fixed arrangement of seats and large distance between first and last lines of seats. However, "shyness" on the Latvian side was compensated by camera work with relevant focus adjustments and close-ups of these students who spoke up. Thus, it went unnoticed by American students whose learning studio classroom, while providing learners with various round tables, used fixed camera. This last excerpt speaks to the symbolic meaning associated with spatial alignment on one's body, in this case, in the technology-mediated presence where "shyness" can be constructed but also avoided with the creative use of technology.

What we see in the above mentioned data excerpts is the reference to particular rhythm, content, and presence in the joint interaction that both sides recognize to be of a specific quality that does not exactly fit to participants' ideals about what counts as a good discussion session. Interestingly, both groups of students pointed at the communicative behavior of themselves and others as being somewhat problematic or "shy". The technological solutions suggested during the separate feedback sessions towards the end of the course were primarily aimed at fixing the shortcomings of the said "shy" communication:

"We didn't know any of those students and perhaps students should be matched and chat online with each other [...]" (LV 2-Feedback notes).

"[...] there [in the class chat room] we could ask [...] questions that did not necessarily pertain to the course [...]" (US 9 TRANS end-of-term).

"[...] it would have been more beneficial if we could have zoomed in on our faces like the Latvian partners did" (US 4 Feedback notes).

The above-mentioned excerpts construct the ideal way of interaction, such as when the use of technology stimulates students "to know" (LV2) each other better by being "matched" (LV2) with each other or by being in smaller online groups that would ensure a possibility "to ask questions" (US9) that not necessarily correspond to the course topics.

While camera work on the ViA side compensated for the distance UMM students might otherwise perceive due to the larger classroom setting on the Latvian side, it was the UMM students who critically and negatively assessed their own visual position in relation to ViA students by comparing the use of close-ups on the ViA side with perceived visual qualities they were lacking on UMM side. The excerpts speak to perceived inferior ways of relating on the US side that create inequality in visual presence, since it is not as "beneficial" (US4) as it could potentially be if the UMM side would use the same technological solutions as their partners in ViA. 
This reveals shared cultural ideals about a proper way of relating, where technology and content of interaction, thereby, should have a task to mimic the processes associated with building interpersonal trust and closeness, thus, assisting in setting up favorable pre-conditions for classroom discussion.

\section{Interpretation}

It is relatively common to hear ViA students criticizing themselves or being characterized by university instructors for being a rather difficult audience in comparison to, for instance, the students in a US university. Some Latvian classroom characteristics include being hesitant to speak up in discussion seminars or in taking the initiative of being first in providing verbal input, by avoiding a public disagreement with a majority opinion, and by having a minimum of nonverbal cues associated with active listening (e.g. often avoiding eye contact with a speaker in front of the audience, very minimal gesturing that signals understanding, agreeing or disagreeing with the said ideas of others). When compared with the UMM classroom, for ViA students during an interaction in their native tongue, having longer pauses and "moments of silence", as well as maintaining a relatively slower rhythm of turn-taking and waiting for someone to speak up first are communication practices that belong to the ordinary mode of interaction. This style of communication was recognized by ViA students themselves as being problematic. They often joked among themselves about their performance before or after the studied discussion sessions and referred to it as "Latvian mentality". Avoiding sitting in the first row, for participants, was also among typical manifestations of the said "mentality" that ViA students upon arriving to class often marked as somehow funny behavior. Still, they almost never opted for a change. Instead, the choice was made to perform more-familiar ritualized communication similar to previous and other classroom discussion experiences, despite the awareness of contrasting or other possibilities.

It has to be noted that the choice to sit in the front line for ViA students potentially presumes the social risks associated with a peer judgment where manifestation of such behaviors can be interpreted as eagerness to show off, to be noticed and be more-liked by the professor. The aforementioned sensibility usually leads to the whole group sitting close together in a somehow safe distance and moving to front seats individually or as a group only after the instructor invites them to do so. If the alignment of the room permits, an instructor instead typically accommodates and moves closer to the students. By contrast, UMM students are more instructed to sit in the front, to gain the instructor's attention, and to raise hands or speak frequently to indicate that they are paying attention or following the ideas of the activity. Although in this course verbal participation was not quantitatively graded, in many courses at UMM it is a usual prerequisite 
that counts towards the final grade. Bearing this in mind, UMM students may not be competitive directly, but are thus keenly aware when they are not given identical opportunities to others in their peer cohort, thus their reaction to the lack of close-ups during Skype discussion. The nature of their understanding of discussion norms became heightened, but not fully-modified to match those of Latvian students.

In the ViA context verbal participation sometimes counts toward the final grade, however, it is not a common practice. Thus, the ViA instructor typically includes alternative forms of participation besides speaking-up in discussions to accommodate for a majority of students who do not feel comfortable with active verbal engagement. If necessary, the instructor asks students to send in questions and comment in a written form, in a majority of classes only the physical presence is counted and becomes part of the final assessment. This provides ViA students with alternative, formally recognized and informally accepted resources for participation in the class activities, such as being present and performing "listening" - something that instructors also reward indirectly by calling out the behaviors that do not correspond with the "listening" such as excessive use of smartphones or laptops and conversing with peers without permission. While discussion sessions in ViA are nevertheless a rather popular learning format for students, it is seen that they can also pose several social risks. For instance, there is a peer/instructor pressure put on the quality of participation whereby one should speak up only if his/her contribution is somehow novel and had not been brought up in the same discussion before. Secondly, one has to be careful with posing questions since they have a potential to cast the inquirer in unfavorable light, e.g. if the question refers to something that the instructor already explained, or if it seems to be too simplistic in the eyes of other class participants. To sum up, there are group identity and status concerns involved for a Latvian student when he/she is put in the position to speak up in the classroom discussion. Finding oneself challenged to satisfy the aforementioned expectations can potentially threaten one's social position. With the demand to interact in a foreign language, this pressure on the ViA side was possibly higher than usual.

In conclusion, when participants jointly problematize their own and each other's communicative behavior as being "shy", the particular cultural code has been relieved. We summarize it in the following cultural premises of existence. Participant counts as "shy" if he/she: (1) interrupts the ideal rhythm of studentinstructor interaction by being silent for too long when asked to participate; (2) fails to provide the classroom discussion with the ideal amount of talk; (3) violates the rules associated with an ideal spatial presence in the learning space where the discussion takes place by avoiding to sit in the first line.

This kind of "shyness" then can be overcome by a particular choice and use of technology that ensures: (4) equality in visual presence by providing close-ups 
of discussion participants; (5) personal interaction in a form of small group chatting and/or chatting about topics outside the course domain.

With these premises in mind, we can further conclude that the content associated with the correct performance of the ritualized discussion session is negotiated around culturally specific uses of silence, social and institutional pressures associated with the amount and content of verbal participation and use of physical space. Fucoult and Melican (2007) see communication technologies as participating in the construction and maintenance of social life by, among other ways, supporting and extending the already existing ritualized practices. The technology in the context of the studied interaction is seen as pertaining to the ritualized aspects of the form and content of the face-to-face discussion session. Its task is to substitute the missing elements from interpersonal communication allowing for building closer and more equal relationships.

This report focuses on communication that has no singular physical place of existence, but which is instead a product of technology-mediated real-time interactions. There were several ways in which the intersections of norms from the local classrooms created a new type of co-constructed and moment-to-moment negotiated cultural rituals pertaining to the specific communication, "talk about talk" or cultural discourse that is produced during the learning interaction in our joint course. In planning to conduct future collaborations of this type, as instructors we will need to be increasingly mindful of recognizing and valuing these elements of the connections and processes that students develop. To foster inclusivity, equality and a democratic educational setting, it becomes necessary to see technical opportunities for international learning partnerships as the beginning of creating shared cultural moments, rather than the solutions themselves.

\section{References}

Alexander, B. K. (1999). Performing Culture in the Classroom: An Instructional (Auto)Ethnography. Text \& Performance Quarterly, 19 (4), 307

Braswell, G. g. (2015). Observations of Representational Practices by Indian-Descent Children in a US Preschool Classroom: Connections Among People, Spaces and Artifacts. Early Childhood Education Journal, 43 (2), 135-142

Cameron, D. (2000). Good to talk? Living and working in a communication culture. Thousand Oaks, CA: Sage

Carbaugh, D. (2007). Cultural discourse analysis: Communication practices and intercultural encounters. Journal of Intercultural Communication Research, 36, 167-182

Carbaugh, D., Berry, M., \& Nurmikari-Berry, M. (2006). Coding Personhood though Cultural Terms and Practices: Silence and Quietude as a Finnish "Natural Way of Being". Journal of Language and Social Psychology. 25, 3, 2003-220

Carbaugh, D. (2005). Cultures in Conversation. NJ: Lawrence Erlbaum 
Carbaugh, D. (1993). Cultural Pragmatics and Intercultural Competence. The Competent Intercultural Communicator: AFinLA Yearbook 1993, (eds. L. Lofman, L. Kurki-Suonio, S. Pellinen, \& J. Lehtonen). Publications de 1'association finlandaise de linguistique applique, 51. 117-129

Cazden, C. B. (2001). The language of teaching and learning. The language of teaching and learning. Communication, 80 (3), 348-369

Covarrubias, P. (2008). Masked Silence Sequences: Hearing Discrimination in College Classroom. Communication, Culture and Critique, 1 (3), 227-252

Damrow, A. (2014). Navigating the Structures of Elementary School in the United States and Japan: An Ethnography of the Particular. Anthropology \& Education Quarterly, 45 (1), 87-104.

Dedze, I., \& Rubene, Z. (2016). Universities in Latvia - from the Soviet to European Higher Education Area. Foro de Educacion, 14 (21), 13-38

Foucault, B., \& Melican, J. (2007). The Digital and the Divine: Taking the Ritual View of Communication and ICT Interaction. HCI

Hall, B. (2005). How can we learn about our own and others' cultures. Among cultures-The challenge of communication, 63-98.

Hymes, D. (1962). The ethnography of speaking. In T. Gladwin, W. C. Sturtevant (Eds.), Anthropology and Human Behavior (pp. 15-53). Washington, DC: Anthropological Society of Washington

Maybin, J. (2013). Towards a sociocultural understanding of children's voice. Language \& Education: An International Journal, 27 (5), 383-397 doi:10.1080/09500782.2012. 704048

Obenchain, K. M., Balkute, A., Vaughn, E., \& White, S. (2016). High School Teachers' Identities: Constructing Civic Selves. The High School Journal, 99 (3), 252-278.

Philipsen, G. (1992). Speaking culturally: Explorations in Social Communication. Albany: State University of New York Press

Philipsen, G. (1997). A Theory of Speech Codes. In Philipsen G., Albrecht T. (Eds.) Developing Communication Theories (pp. 119-156). Albany: State University of New York Press

Schildkraut, D. J. (2007). Defining American Identity in the Twenty-First Century: How Much "There" is There? Journal of Politics, 69 (3), 597-615

Spencer, M. B. (2011). American identity: Impact of youth's differentia; experiences in society on their attachment to American ideals. Applied developmental science, 15, (2), 61-69

Turner, V. (1980). Social Dramas and Stories about Them. Critical Inquiry, Vol. 7, No. 1, 141168

Waisbord, S. (2016). Communication Studies without Frontiers? Translation and Cosmopolitanism across Academic Cultures. International Journal of Communication, Vol 10, 868-886 